\title{
Altered Polyamine Profiles in Colorectal Cancer
}

\author{
MARKUS K. VENÄLÄINEN ${ }^{1,2}$, ANTTI N. ROINE ${ }^{3}$, MERJA R. HÄKKINEN ${ }^{4}$, \\ JOUKO J. VEPSÄLÄINEN ${ }^{4}$, PEKKA S. KUMPULAINEN ${ }^{5}$, MIKKO S. KIVINIEMI ${ }^{6}$, \\ TERHO LEHTIMÄKI ${ }^{7,8}$, NIKU K. OKSALA ${ }^{8,9,10^{*}}$ and TUOMO K. RANTANEN ${ }^{1,2,11^{*}}$ \\ ${ }^{1}$ Department of Surgery, School of Medicine, and ${ }^{4}$ School of Pharmacy, \\ University of Eastern Finland, Kuopio, Finland; \\ Departments of ${ }^{2}$ Surgery, and ${ }^{6}$ Gastroenterology, Kuopio University Hospital, Kuopio, Finland; \\ ${ }^{3}$ Department of Surgery, Hatanpää Hospital, Tampere, Finland; \\ ${ }^{5}$ Department of Automation Science and Engineering, University of Technology, Tampere, Finland; \\ ${ }^{7}$ Department of Clinical Chemistry, Fimlab Laboratories, Tampere, Finland; \\ ${ }^{8}$ Finnish Cardiovascular Research Center Tampere, and ${ }^{9}$ Department of Surgery, \\ Faculty of Medicine and Life Sciences, University of Tampere, Tampere, Finland; \\ ${ }^{10}$ Department of Vascular Surgery, Tampere University Hospital, Tampere, Finland; \\ ${ }^{11}$ Seinäjoki Central Hospital, Seinäjoki, Finland
}

\begin{abstract}
Background: The declining mortality rate of patients with colorectal cancer (CRC) can be explained, at least partially, with early diagnosis. Simple diagnostic methods are needed to achieve a maximal patient participation rate in screening. Materials and Methods: Liquid chromatography electrospray tandem mass spectrometry ( $L C$ $M S / M S)$ was used to determine urinary polyamine (PA) profiles. In a prospective setting, 116 patients were included in the study: 57 with CRC, 13 with inflammatory bowel disease (IBD), 12 with adenoma, and 34 controls. Results: N1,N12-diacetylspermine (DiAcSPM) level was significantly higher in patients with CRC than controls (sensitivity $=78.0 \%$, specificity $=70.6 \% ; p=0.00049)$. The level of diacetylated cadaverine $(p=0.0068)$ was lower and that of diacetylated putrescine ( $p=0.0078$ ) was higher in patients with CRC than in those with IBD. Cadaverine $(p=0.00010)$ and spermine $(p=0.042)$ levels were lower and that of DiAcSPM $(p=0.018)$ higher in patients with CRC than in those with adenoma. Conclusion: The simultaneous determination of urinary PAs by means of LC-MS/MS can be used to discriminate CRC from controls and patients with benign colorectal diseases.
\end{abstract}

*These Authors contributed equally to this study.

Correspondence to: Professor Tuomo Rantanen (ORCID 00000001-6390-1373), Department of Surgery, Kuopio University Hospital, Box 100, 70029 KYS, Finland. Tel: +358 17173311, Fax: +358 17172611, e-mail: tuomora@gmail.com

Key Words: Colorectal cancer, inflammatory bowel disease, polyamines, diagnostic methods.
Colorectal cancer (CRC) is the third commonest type of cancer worldwide, with 1.4 million patients and 694,000 deaths in 2012 (1). Although the CRC incidence rate has generally declined, its incidence has increased in Western Asia, Eastern Europe and Scandinavian countries (2-7). Despite the high incidence of CRC in developed countries, its annual mortality rate declined between 2000 and 2009, by 3\% (8). The decrease can be partially explained by improved screening and early diagnosis $(2,4-7)$. However, the complexity of the screening, for instance, patient bowel preparation, lowers the screening rates. According to previous studies, the participation rates in screening through fecal immunochemical testing and colonoscopy have been low, amounting to approximately $34 \%$ and $25 \%$, respectively $(9,10)$. An easier diagnostic method could increase participation rates.

Polyamines (PAs) are molecules that are indispensable in normal cell growth, gene expression and cell proliferation. The transition from healthy cell to tumor requires particularly increased cell proliferation. Because PAs are needed in cell proliferation, their concentrations increase during the transition from a healthy to a tumor cell $(11,12)$.

PAs can exist as either free or conjugated forms in cells and physiological fluids, but in urine, they are mainly excreted in their acetylated forms. The concentrations of free PAs are also increased in many benign disorders. Recently, it was shown that the level of acetylated PAs is more specific for cancer. For example, $N^{1}, N^{12}$-diacetylspermine (DiAcSPM) was found to be increased in CRC and also in dysplastic colorectal lesions $(13,14)$.

Our group has developed and validated a novel liquid chromatography electrospray tandem mass spectrometry (LCMS/MS) method for the simultaneous analysis of 14 PAs in 
Table I. Clinicopathological data and median urinary creatinine of patients with colorectal cancer ( $n=57)$, with adenoma ( $n=12)$ and patients with inflammatory bowel disease $(n=13)$.

\begin{tabular}{|c|c|c|c|c|c|c|c|c|}
\hline Type & $\begin{array}{l}\text { Colonic cancer, n } \\
\text { Left-sided, } 16 \\
\text { Right-sided, } 14 \\
\text { Undetermined, } 8\end{array}$ & $\begin{array}{l}\text { Rectal cancer, n } \\
\text { Rectal, } 16 \\
\text { Recto-sigmoid, } 3\end{array}$ & Type* & $\begin{array}{l}\text { denoma, n } \\
\text { Tubular } \\
\text { ule-villosus } \\
\text { ibular and } \\
\text { ulovillosus }\end{array}$ & $\begin{array}{l}5 \\
5 \\
1\end{array}$ & Type & $\begin{array}{l}\text { IBD, n } \\
\text { UC } \\
\text { Crohn } \\
\text { Ischemic }\end{array}$ & $\begin{array}{l}9 \\
3 \\
1\end{array}$ \\
\hline \multicolumn{9}{|l|}{ Histological grade } \\
\hline I & 1 & 2 & No. of adenomas & 1 & 9 & Location & Proctitis & 0 \\
\hline II & 34 & & & $>1$ & 3 & & Left-sided & 7 \\
\hline III & 3 & 2 & Grade of dysplasia* & Low & 10 & & Right-sided & 2 \\
\hline IV & 0 & 1 & & High & 1 & & Whole colon & 4 \\
\hline \multicolumn{9}{|l|}{ Stage } \\
\hline IA & 6 & 1 & & & & Severity & Mild & 1 \\
\hline IB & 4 & 4 & & & & & Moderate & 6 \\
\hline IIA & 8 & 8 & & & & & Severe & 6 \\
\hline IIB & 2 & 0 & & & & & & \\
\hline IIIA & 6 & 0 & & & & & & \\
\hline IIIB & 8 & 5 & & & & & & \\
\hline IV & 4 & 0 & & & & & & \\
\hline Urinary creatinine $(\mu \mathrm{mol} / \mathrm{l})$ & 7513 & 9993 & & & 6712 & & & 9296 \\
\hline
\end{tabular}

UC: Ulcerative colitis. *No histological data for one case.

urine, including their mono-and diacetylated forms (15). Using this method, we were able to distinguish between benign and malignant ovarian tumors (16). Our LC-MS/MS method utilizes deuterated internal standards in quantitation. Fourteen individual PAs including their mono- and diacetylated metabolites can be analyzed in a single analytical run, which differentiates our method from previous ones.

The aim of this prospective study was to investigate all urinary free, mono-and diacetylated PAs using this LC-MS/MS method in patients with CRC and compare them against controls and the most important benign differential diagnostic options [adenoma, inflammatory bowel disease (IBD). Our primary hypothesis was that the comprehensive PA profiles would be able to discriminate healthy controls from patients with CRC and from those with benign diseases, and that curative resection of CRC would be reflected in the postoperative PA levels. A secondary hypothesis was that benign colorectal disorders could be discriminated from each other.

\section{Materials and Methods}

Study population. The study population was recruited from the Seinäjoki Central Hospital between 6 Apr 2013 and 11 Jul 2015 and from Kuopio University Hospital between 9 May 2014 and 16 July 2015. Written, informed consent was obtained from all patients for participation and use of tissues and data.

The inclusion criteria were active $\mathrm{CRC}$, IBD, or colonic adenoma $>1 \mathrm{~cm}$ or two smaller adenomas. Eighty patients with CRC, 20 with adenomas, 20 with IBD and, for the control group, 20 patients scheduled for either an inguinal or ventral hernia operation and 20 patients scheduled for laparoscopic cholecystectomy were included in the study. All controls were without symptoms (diarrhea, constipation, irregular bowel movements) related to the lower gastrointestinal tract.

The exclusion criteria were a failure in sample collection due to reasons related to the patient (long distance) or the staff (samples were not taken, samples were not frozen), or due to other mistakes in sample collection. Forty-four patients were excluded due to a failed urine sample. Finally, 116 patients were included in the study: 57 with CRC ( 38 colonic, 19 rectal), 13 with IBD, 12 with adenoma and 34 controls (19 patients scheduled for hernia repair and 15 for laparoscopic cholecystectomy). In addition, for 33 patients (21 colonic cancer, 12 rectal cancer), both pre-and postoperative urine samples were taken. According to Finnish standards, the postoperative carcinoembryonic antigen (CEA) samples were taken 2-3 months after the curative operation. The included and excluded patients did not differ from each other as regards sex and age.

Clinicopathological data on the included patients with CRC, adenoma and IBD are shown in Table I. The severity of IBD was defined using the Mayo Score (ulcerative colitis) (17) and simplified endoscopic activity score for Crohn's disease (18). Adenomas and CRC were defined using the WHO classification (19).

Patients with CRC or an adenoma as well as the control group gave one urine sample before the surgical procedure. In addition, patients with IBD gave one urine sample when they were referred for lower gastrointestinal endoscopy. For the surgical patients, a postoperative urine sample was taken 2-3 months after the curative surgical procedure.

The patients provided routine morning urine samples, or samples where the urine had remained in the bladder for at least 4 hours, and the samples were stored within 2 hours in the laboratory at -70 $-80^{\circ} \mathrm{C}$ until analysis. Urine was collected prospectively without preservatives. All patients were on unreported self-selected diets. 
Table II. Median raw (IQR) and creatinine-normalized polyamine (PA) levels in controls, patients with inflammatory bowel disease, adenoma, and colorectal cancer $(C R C)$ preoperatively and postoperatively. Three polyamines [acetylpermine (AcSPM), 1,3-diaminopropane (DAP) and putrescine $(P U T)]$ were excluded because of an inadequate number of samples.

\begin{tabular}{|c|c|c|c|c|c|c|c|c|c|c|}
\hline \multirow[b]{2}{*}{ PA } & \multicolumn{2}{|c|}{ Control } & \multicolumn{2}{|c|}{ IBD } & \multicolumn{2}{|c|}{ Adenoma } & \multicolumn{2}{|c|}{ CRC-preoperative } & \multicolumn{2}{|c|}{ CRC-postoperative } \\
\hline & $\mathrm{nmol} / 1$ & $\begin{array}{c}\mu \mathrm{mol} / \mathrm{g} \\
\text { creatinine }\end{array}$ & $\mathrm{nmol} / 1$ & $\begin{array}{c}\mu \mathrm{mol} / \mathrm{g} \\
\text { creatinine }\end{array}$ & $\mathrm{nmol} / 1$ & $\begin{array}{c}\mu \mathrm{mol} / \mathrm{g} \\
\text { creatinine }\end{array}$ & $\mathrm{nmol} / 1$ & $\begin{array}{c}\mu \mathrm{mol} / \mathrm{g} \\
\text { creatinine }\end{array}$ & $\mathrm{nmol} / 1$ & $\begin{array}{c}\mu \mathrm{mol} / \mathrm{g} \\
\text { creatinine }\end{array}$ \\
\hline DiAcPUT & $81.8(92.5)$ & 0.0919 & $169.4(162.7)^{\mathrm{a}}$ & $0.190^{\mathrm{ab}}$ & $61.7(167.1)$ & 0.103 & $86.0(76.2)^{\mathrm{c}}$ & $0.101^{\mathrm{cd}}$ & 89.9 (147.9) & 0.110 \\
\hline DiAcCAD & $28.3(62.9)$ & 0.0351 & $91.9(161.9)^{\mathrm{cab}}$ & 0.0768 & $30.0(6.9)$ & 0.0375 & $20.7(55.0)^{\mathrm{c}}$ & 0.0273 & $42.0(103-6)$ & 0.0461 \\
\hline DiAcSPD & $215.4(236.9)$ & 0.217 & $233.2(544.0)$ & $0.363^{\mathrm{a}}$ & $293.3(322.8)$ & 0.235 & 278.7 (325.9) & $0.307^{\mathrm{a}}$ & $278.6(216.0)$ & 0.325 \\
\hline DiAcSPM & 74.4 (130.49) & 0.0855 & $101.8(270.6)$ & $0.163^{\mathrm{ab}}$ & $76.0(95.8)$ & 0.0970 & $170.0(189.6)^{\mathrm{abd}}$ & $0.182^{\mathrm{abd}}$ & d $100.0(341.7)$ & 0.101 \\
\hline AcPUT & 9182.7 (10296.6) & 10.0 & $8806.4(12037.9)$ & $13.1^{\mathrm{a}}$ & $9754.1(12956.9)$ & $8.55 \quad 1$ & $10345.7(11229.3)$ & $11.1^{\mathrm{a}} \quad 1$ & $10058.5(6278.0)$ & 10.7 \\
\hline AcCAD & $643.1(1257.8)$ & 0.605 & $1387.5(2339.5)^{\mathrm{a}}$ & $1.17^{\mathrm{ab}}$ & $464.1(1346.6)$ & 0.475 & $674.0(1764.3)$ & $0.692^{\mathrm{b}}$ & $1126.0(3484.7)$ & 1.17 \\
\hline$N^{1} \mathrm{AcSPD}$ & $3074.2(2483.9)$ & 3.09 & $1397.2(5339.3)$ & 4.04 & $2664.3(3235.7)$ & 3.74 & $3720.4(3112.6)$ & $37.9^{\mathrm{a}}$ & $2123.8(2798.7)$ & 3.53 \\
\hline$N^{8} \mathrm{AcSPD}$ & $2348.1(1959.8)$ & 2.52 & $2483.9(3372.3)$ & 2.87 & $2319.8(3246.3)$ & 2.25 & $2691.1(2203.6)$ & $3.08^{\mathrm{ab}}$ & $2591.7(1970.7)$ & 3.14 \\
\hline CAD & $59.9(175.4)$ & 0.0819 & $110.7(624.8) \mathrm{c}$ & $0.215^{\mathrm{a}}$ & $314.0(131.0)^{\mathrm{ba}}$ & $0.438^{\mathrm{a}}$ & $72.9(72.9)^{\mathrm{a}}$ & $0.0968^{\mathrm{b}}$ & $82.5(169.3)$ & 0.107 \\
\hline SPD & $176.9(188.3)$ & 0.167 & $158.7(224.3)$ & 0.190 & $216.1(214.5)$ & 0.167 & $188.1(190.7)^{\mathrm{d}}$ & 0.187 & $139.3(128.9)$ & 0.167 \\
\hline SPM & $109.1(88.0)$ & 0.238 & $221.9(263.8)$ & 0.346 & $516.4(1418.5)^{b}$ & $0.349^{\mathrm{a}}$ & $133.0(706.6)^{b}$ & 0.129 & $192.6(196.9)$ & 0.130 \\
\hline
\end{tabular}

DiAcPut: Diacetylputrescine, DiAcCAD: diacetylcadaverine, DiAcSPD: diacetylspermidine, DiAcSPM: diacetylspermine, AcPUT: acetylputrescine, AcCAD: acetylcadaverine, $N^{1}$ AcSPD: $N^{1}$-acetylspermidine, $N^{8}$ AcSPD: $N^{8}$-acetylspermidine, CAD: cadaverine, SPD: spermidine, SPM: spermine. Significantly different at $p<0.05:{ }^{\mathrm{a}} v s$. Controls, ${ }{ }_{v s}$. adenoma, ${ }^{\mathrm{c}}{ }_{v s}$. CRC, ${ }^{\mathrm{d}}{ }_{v s}$. Post-op. Creatinine-normalized PA levels ( $\mu$ mol/g creatinine) were calculated using the equation: PA conc. $(\mathrm{nmol} / \mathrm{l}) /[$ creatinine conc. $(\mu \mathrm{mol} / \mathrm{l}) * 113.1 \mathrm{~g} / \mathrm{mol} / 1000]$.

Three patients had undergone long-term chemoradiotherapy and four short-term radiotherapy before rectal surgery and also before giving the preoperative urinary sample. Before sample preparation, the urine specimens were thawed unassisted at room temperature and centrifuged at $13,000 \mathrm{rpm}$ for $5 \mathrm{~min}$ at $20^{\circ} \mathrm{C}$. In addition, creatinine concentration in urine was measured enzymatically using Cobas 6000, C 501-module (Roche Diagnostics GmbH, Mannheim, Germany) to determine in effect of kidney function. Using the creatinine concentrations, PA concentrations were normalized allowing comparison in parallel with the raw results. The normalized results were reported as $\mu \mathrm{mol} / \mathrm{g}$ creatinine.

Determination of PAs. A detailed description of the LC-MS/MS method has been published elsewhere (15). The method has been validated according to the Food and Drug Administration guidelines. Following Pas were analysed: diacetylputrescine (DiAcPU), diacetylcadaverine (DiAcCAD), diacetylspermidine (DiAcSPD), diacetylspermine (DiAcSPM), acetylputrescine, (AcPUT), acetylcadaverine (AcCAD), $\mathrm{N}^{1}$-acetylspermidine ( $\mathrm{N}^{1}$-AcSPD), $\mathrm{N}^{8}$ acetylspermidine ( $\mathrm{N}^{8}$-AcSPD), cadaverine (CAD), spermidine (SPD), spermine (SPM), acetylspermine (AcSPM), 1,3diaminopropane (DAP) and putrescine (PUT). The standards and calibration curve quality control samples were made using water as a diluent, and urine-based quality control samples were made using pooled urine samples spiked with PA standards, without spiking, and by diluting with water. Calibration standards were analyzed before and after the urine samples within each analysis, and quality control samples between the study samples. Solid-phase extraction cartridges were used in sample preparation to remove impurities. Calibration ranges and limit-of-quantitation values were used for all 14 PAs, as described elsewhere (15). The acceptance value for intraand inter-run precision and accuracy were set to $<15 \%$ and $85 \%$ $115 \%$, respectively. An exception was made for the lowest calibration point where the precision and accuracy were $<20 \%$. Three PAs (AcSPM, DAP and PUT) in the samples had concentrations that were below the lower limit of quantitation of our method and were thus excluded from further analysis.

Statistical analysis. Values are presented as median and interquartile range (IQR). In the statistical analysis, the non-parametric Wilcoxon rank-sum test was used. The significance level was set at $p<0.05$. For each statistically significant difference in PA concentration, sensitivities and specificities were reviewed. Receiver operating characteristic (ROC) curve analyses were performed and the area under the curve (AUC) was measured for those PAs.

Ethics. The study was approved by the Ethical Committee of Tampere University Hospital (R10066).

\section{Results}

Patient characteristics. The group of patients with CRC consisted of 33 men and 24 women (median age $=70$ years), while that with IBD of seven men and five women (median age $=43.5$ years), with adenoma of six men and five women (median age $=70.5$ years) and the control group of 17 men and 17 women (median age $=57$ years), respectively.

The effect of CRC. DiAcSPM (sensitivity=78\%, specificity= $70.6 \%, p=0.00049$; $\mathrm{AUC}=0.72$ ) was higher in patients with $\mathrm{CRC}$ when compared to the control group. The creatininenormalized concentrations of AcPUT, DiAcSPD, N1AcSPD and N8AcSPD were significantly higher than those of the control group (Table II, Figure 1). 


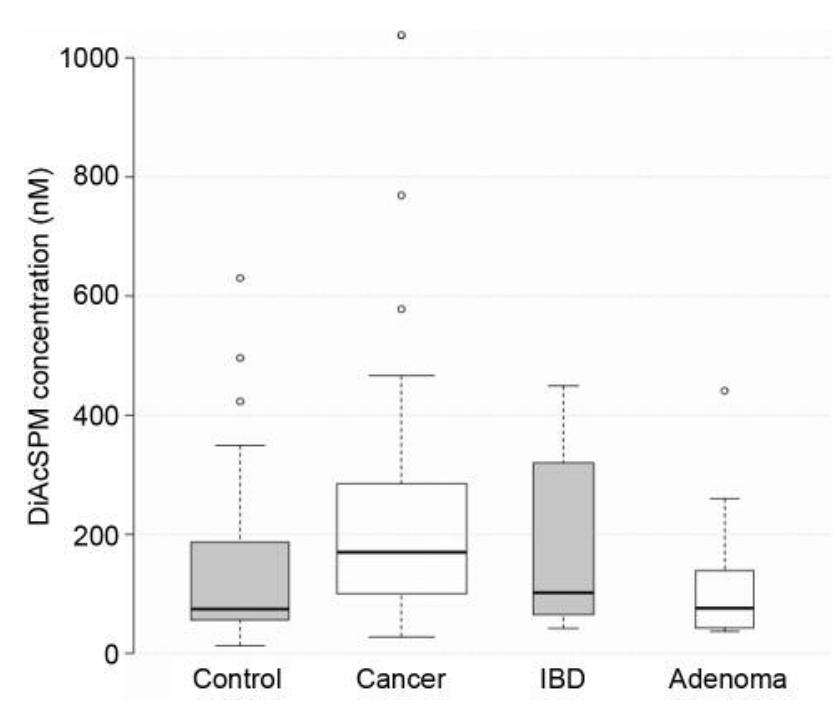

Figure 1. Diacetyl spermine (DiAcSPM) concentrations in control, patients with colorectal cancer, inflammatory bowel disease and adenoma. The upper and lower box boundaries show the 75th and 25th percentiles, a plus sign indicates the mean, and a horizontal line indicates the median value. The upper and lower bars indicate the highest and lowest concentrations. Circles present outliers that fall outside 1.5 times the interquartile range above the upper quartile.

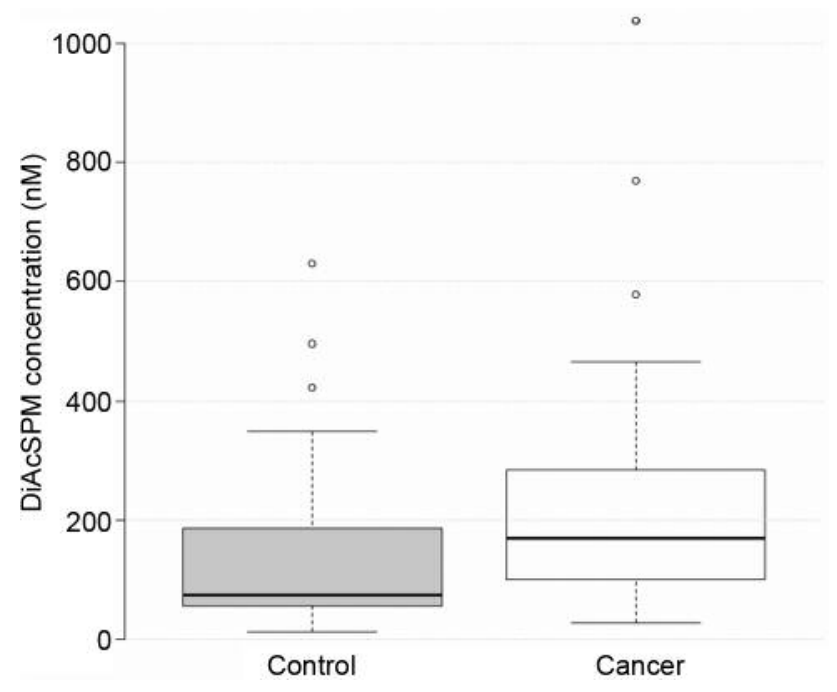

Figure 2. Diacetyl spermine (DiAcSPM) concentrations in urine from patients before and after curative resection with colorectal cancer. The upper and lower box boundaries show the 75th and 25th percentiles, a plus sign indicates the mean, and a horizontal line indicates the median value. The upper and lower bars indicate the highest and lowest concentrations. Circles present outliers that fall outside 1.5 times the interquartile range above the upper quartile.
$\operatorname{DiAcCAD}(p=0.0068)$ and DiAcPUT $(p=0.0078)$ were significantly lower in patients with CRC than in those with IBD. For the creatinine-normalized concentration, differences in DiAcCAD did not reach statistical significance, but DiAcPUT showed the same pattern (Table II).

CAD $(p=0.0001)$ and spermine $(p=0.042)$ concentrations were lower and DiAcSPM $(p=0.018)$ higher in patients with $\mathrm{CRC}$ than in those with adenoma. In addition, raw AcCAD and $\mathrm{N}^{8}$ AcSPD concentrations in urine were higher in patients with CRC than in those with adenoma when compared with the creatinine-normalized concentrations.

The effect of IBD. DiAcPUT (sensitivity $=53.8 \%$, specificity= $88.2 \%, p=0.0056 ; \mathrm{AUC}=0.76$ ), DiAcCAD (sensitivity $=0 \%$, specificity $=97.1 \%, p=0.033 ; \mathrm{AUC}=0.70)$, and AcCAD $($ sensitivity $=23.1 \%$, specificity $=94.1 \%, p=0.020 ; \mathrm{AUC}=0.72)$ were higher in patients with IBD than in controls. For the creatinine-normalized results, AcPUT, DiAcSPD, CAD, and DiAcSPM concentrations were found to be higher in patients with IBD when compared to the control group (Table II).

$\mathrm{CAD}$ was higher in patients with adenoma than in controls (sensitivity $=75.0 \%$, specificity $=82.4 \%, p=0.0042$; $\mathrm{AUC}=0.78$ ). Spermine concentration was also higher in patients with adenoma when using the creatinine-normalized concentration (Table II).

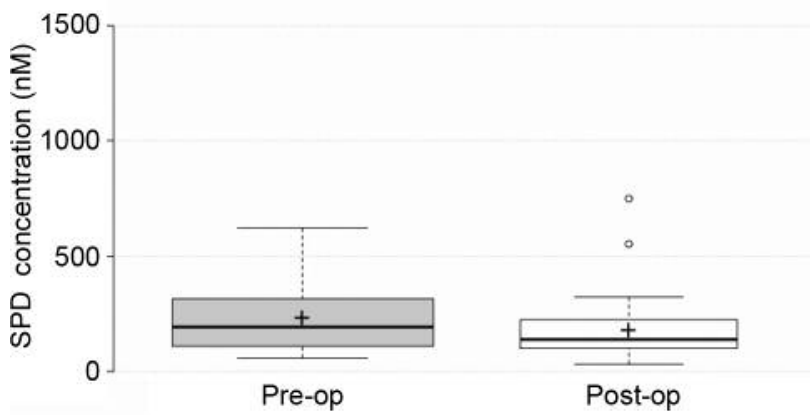

Figure 3. Spermidine (SPD) concentrations in urine from patients before and after curative resection with colorectal cancer. The upper and lower box boundaries show the 75 th and 25th percentiles, a plus sign indicates the mean, and a horizontal line indicates the median value. The upper and lower bars indicate the highest and lowest concentrations. Circles present outliers that fall outside 1.5 times the interquartile range above the upper quartile.

DiAcCAD was higher in patients with IBD than in patients with adenomas $(p=0.019$; Table II). However, with the creatinine-normalized results DiAcCAD did not show significant differences but DiAcPUT, AcCAD, and DiAcSPM were higher in patients with IBD than in those with adenoma. 
Table III. Median (IQR) levels (nmol/l) of 11 polyamines (PA) in controls, patients with colorectal cancer (CRC) and all patients according to sex. Three polyamines [acetylpermine (AcSPM), 1,3-diaminopropane (DAP) and putrescine (PUT)] were excluded because of an inadequate number of samples.

\begin{tabular}{lcccccc}
\hline & \multicolumn{2}{c}{ Controls } & \multicolumn{2}{c}{ CRC } & Overall \\
\cline { 2 - 7 } PA & Men & Women & Men & Women & Men & Women \\
\hline DiAcPUT & $69.2(91.5)$ & $102.6(96.0)$ & $88.0(106.9)$ & $77.7(86.7)$ & $86.4(106.9)$ & $102.1(108.1)$ \\
DiAcCAD & $28.9(77.1)$ & $14.3(68.0)$ & $27.1(43.3)$ & $21.5(59.8)$ & $30.0(53.4)$ & $30.2(74.8)$ \\
DiAcSPD & $165.6(160.3)$ & $268.2(274.5)$ & $294.3(311.1)$ & $202.2(322.0)$ & $237.5(351.4)$ & $287.3(313.9)$ \\
DiAcSPM & $70.2(61.8)$ & $81.6(158.5)$ & $157.2(191.4)$ & $169.3(202.8)$ & $105.9(165.7)$ & $114.8(185.4)$ \\
AcPUT & $8059.9(7155.4)$ & $14114.7(9823.5)$ & $10822.4(10049.2)$ & $8605.7(15611.6)$ & $9926.9(9669.8)$ & $10775.9(12294.4)$ \\
AcCAD & $720.4(1303.0)$ & $482.7(1046.1)$ & $544.0(1844.8)$ & $899.6(1604.6)$ & $734.0(1575.0)$ & $899.7(1482.6)$ \\
$N^{1}$ AcSPD & $3519.1(2140.0)$ & $2839.6(2365.2)$ & $4415.4(3429.2)^{\mathrm{b}}$ & $2972.3(2365.2)$ & $3706.4(3889.4)$ & $3292.2(3011.2)$ \\
$N^{8}$ AcSPD & $2250.7(2153.1)$ & $3272.8(2022.2)$ & $3294.8(2674.8)^{\mathrm{b}}$ & $2190.7(1908.7)$ & $2743.1(2649.6)$ & $2293.3(2333.7)$ \\
CAD & $52.4(12.6)$ & $156.1(303.7)$ & $52.4(31.9)^{\mathrm{b}}$ & $160.4(186.5)$ & $52.4(51.7)^{\mathrm{c}}$ & $178.2(259.8)$ \\
SPD & $182.2(225.0)$ & $152.7(178.2)$ & $282.9(216.0)^{\mathrm{b}}$ & $114.2(109.4)$ & $224.3(206.7)^{\mathrm{c}}$ & $149.0(146.1)$ \\
SPM & $937.4(1038.4)^{\mathrm{a}}$ & $64.4(23.5)$ & $582.2(1175.0)^{\mathrm{b}}$ & $50.9(21.4)$ & $496.1(1035.8)^{\mathrm{c}}$ & $53.5(21.2)$ \\
\hline
\end{tabular}

DiAcPut: Diacetylputrescine, DiAcCAD: diacetylcadaverine, DiAcSPD: diacetylspermidine, DiAcSPM: diacetylspermine, AcPUT: acetylputrescine, AcCAD: acetylcadaverine, N1 AcSPD: $N^{1}$-acetylspermidine, $N^{8} \mathrm{AcSPD}: N^{8}$-acetylspermidine, CAD: cadaverine, SPD: spermidine, SPM: spermine. Significantly different at $p<0.05:{ }^{\mathrm{a}} v s$. Control women, ${ }^{\mathrm{b}} v$. CRC women, ${ }^{\mathrm{c}} v s$. all women.

The effect of surgical treatment. DiAcSPM $(p=0.00016)$ and spermidine $(p=0.046)$ were lower in patients after a curative operation for CRC than preoperatively. Results for creatinine-normalized and raw concentrations in urine did not differ when comparing the pre-and postoperative samples (Table II, Figures 2 and 3).

The effect of sex. CAD $(p=0.004)$ was lower among men in both control and CRC groups, while spermine was higher in men of control $(p<0.001)$ and CRC $(p<0.001)$ groups than in the corresponding women. In addition, N1AcSPD $(p=0.025)$ and $\mathrm{N}^{8} \mathrm{AcSPD}(p=0.02)$ were higher in men with $\mathrm{CRC}$ than in women with CRC (Table III).

The effect of location of cancer. AcPUT ( $p=0.029)$ was higher in patients with rectal cancer (median=17690 nmol/l) than in those with colonic cancer (median=9927 nmol/1), when all rectal cancer cases were included. The AcPUT $(p=0.019)$ values were also significantly different (median $=17890 \mathrm{vs}$. $9927 \mathrm{nmol} / \mathrm{l}$ ) when patients with rectal cancer with preoperative treatment were excluded. When both preoperative treatment methods (long-term chemoradiotherapy and shortterm radiotherapy) were included, the preoperative treatment group had lower DiAcSPD (median=439.3 vs. $278.5 \mathrm{nmol} / \mathrm{l}$; $p=0.015), \quad \mathrm{N}^{1}$ AcSPD (median $=4,976$ vs. 3,757 nmol/l; $p=0.020$ ) and N8AcSPD (median=4,057 vs. 2,256 nmol/1; $p=0.011$ ) compared to those patients with rectal cancer who had received no preoperative treatment.

CAD was higher in stage I (median=178.2 nmol/1) when compared to stage II (median $=52.4 \mathrm{nmol} / 1 ; p=0.009$ ) and stage III (median=52.4 nmol/1; $p=0.0047)$, while DiAcSPM was lower in stage I (median=134.8 $\mathrm{nmol} / \mathrm{l}$ ) than in stage II (median=215 nmol/1; $p=0.0038$ ).

\section{Discussion}

With the simultaneous analysis of 14 urinary PAs, including their acetylated forms, by means of LC-MS/MS, we were able to separate patients with $\mathrm{CRC}$ from the control group and also from the most important benign differential diagnostic alternatives. Additionally, patients with non-malignant colonic diseases were differentiated from each other and from the controls.

DiAcSPM has been demonstrated a promising biomarker for CRC. DiAcSPM performed better than CEA and cancer antigen 19-9 (CA19-9), with a sensitivity of $75.8 \%$ and specificity of $77 \%$, while CEA and CA19-9 had sensitivities of $39.5 \%$ and $14.1 \%$, respectively (13). Unfortunately, specificities of CEA and CA 19-9 were not mentioned in that study. The study included 248 patients with CRC and 51 controls, but the control group also included patients with benign diseases such as IBD or adenoma (13). In our study, DiAcSPM had a sensitivity of $78.0 \%$ and specificity of $70.6 \%$, which are well comparable with these figures. No comprehensive PA profiles have been previously documented for individual colorectal diseases, and benign disorders could thus not be separated from each other. In fact, acute inflammation increases PA levels, which can cause further problems when trying to discriminate between CRC and IBD (13). Our method of simultaneous analysis of 14 urinary PAs for CRC, IBD, adenoma and controls by means of LCMS/MS could help in discrimination between CRC and benign colorectal diseases. Proliferation increases along the 
adenoma-carcinoma sequence among patients with familial adenomatous polyposis (20). In addition, PAs are related to cell proliferation (21).

Our findings that most of the PAs were found at higher levels in CRC than in adenoma are well in accordance with previous studies that have demonstrated that cellular proliferation increases along the adenoma-carcinoma sequence (20) and that PA levels correlate with proliferation (21). Our findings give new information about the pathophysiology of $\mathrm{CRC}$, since PA profiles in benign and malignant colorectal diseases have not been studied previously to our knowledge.

Both in the study by Hiramatsu et al. (13) and in the present study, the sensitivity of DiAcSPM was at least $75 \%$, thus allowing its use in the diagnostic workup of patients with CRC. A commercial enzyme-linked immunosorbent assay for DiAcSPM is now available (22) and might be used to determine DiAcSPM concentration when LC-MS/MS is unavailable. However, DiAcSPM is not specific for CRC, since it is also increased in non-small-cell lung cancer (23), which has to be taken into account in the differential diagnosis of CRC.

We also found differences in PA levels between the nonmalignant colorectal diseases. For example, AcPUT, DiAcSPD, CAD and DiAcSPM separated IBD from the control group, and CAD separated those with adenoma from the control group. Additionally, DiAcPUT, AcCAD and DiAcSPM differed between patients with IBD and those with adenoma. In addition, the respective sensitivity and specificity of CAD in differentiating adenoma from the controls were $75 \%$ and $82.4 \%$, which, as such, is a very promising result, although our patient numbers were quite low. The results of the present study indicate that different PAs are elevated in different colorectal diseases and therefore this phenomenon could aid in diagnosis. To the best of our knowledge, this is reported for the first time herein.

In the present study, DiAcSPM and spermidine levels were lower in patients after curative resection of CRC. Our findings indicate that the LC-MS/MS method might be used not only for the primary diagnosis of CRC but also as a diagnostic tool in the follow-up of patients after curative resection of CRC. In addition, DiAcSPD, $\mathrm{N}^{1}$ AcSPD and $\mathrm{N}^{8}$ AcSPD were lower among patients with rectal cancer who had received preoperative oncological treatment when compared to those who were operated on without these treatments. Future studies are needed to investigate whether these PAs could also be used as a diagnostic tool in the follow-up of patients after oncological treatment for CRC, since our patient numbers in these categories were too low to draw conclusions regarding this matter. The association of increased PA synthesis with cancer has been known for a long time. In fact, PAs mediate the expression of proto-oncogenes related to CRC (24) and proto-oncogene expression is also related to PA metabolism in CRC (25). The modulation of PA synthesis is a potential mode of treatment in cancer types in which differing PA levels are found (26), which further increases the importance of the results of our study.
The limitation of our study is the small number of patients and the few urine samples collected after curative resection of CRC. Therefore, our subgroup analysis (stage, colonic vs. rectal cancer, and sex) should be interpreted with caution. Although statistically significant differences were found between patients with CRC, controls as well as IBD and patients with adenoma, a larger multicenter study is needed to more accurately define the PA levels and profiles of each disease. This could allow the use of only one or some PAs instead of 14 PAs in the diagnostics of both benign and malign colorectal diseases. In addition, our patients were not on any standardized diet before sampling, which could be a source of bias. However, in a previous study, no positive association between dietary PAs and CRC was found (27). Finally, the results concerning DiAcCAD and DiAcPUT should be interpreted with caution, since their analysis was only semiquantitative (15).

The strength of our study was that we were able to simultaneously analyze 14 PAs and the fact that our study was prospective, thus allowing all patient-related aspects to be reliably identified. In addition, using the creatinine concentrations, we were able to normalize the PA concentrations and compare them in parallel with the raw results. Although normalization using urinary creatinine may serve poorly in the case of PAs (28), we found that in CRC, creatinine concentration had an effect on the results.

\section{Conclusion}

Urinary PAs determined by means of LC-MS/MS can be used to discriminate between controls and patients with CRC or non-malignant colorectal diseases. Furthermore, this method can be used to separate non-malignant diseases from each other and follow treatment responses among patients after a curative operation for CRC. In addition, the sensitivity and specificity of some PAs, especially DiAcSPM, were adequate to start using them as diagnostic tools for patients with CRC. However, due to the relatively small number of patients herein, a larger study is needed before adopting this method for routine use.

\section{Conflicts of Interest}

None declared.

\section{Funding Statement}

The study was funded by the EVO funding of the Hospital District of South Ostrobothnia.

\section{References}

1 Ferlay J, Soerjomataram I, Dikshit R, Esewr S, Mathers C, Rebelo M, Parkin D, Forman D and Bray F: Cancer incidence and mortality worldwide: Sources, methods and major patterns in GLOBOCAN 2012. Int J Cancer 136: E359-E386, 2015. 
2 Edwards BK, Ward E, Kohler BA, Eheman C, Zauber A, Anderson R, Jemal A, Schymura M, Lansdorp-Vogelaar I, Seeff L, van Ballegooijen M, Goede S and Ries L: Annual report to the nation on the status of cancer, 1975-2006, featuring colorectal cancer trends and impact of interventions (risk factors, screening, and treatment) to reduce future rates. Cancer 116: 544-573, 2010.

3 Center MM, Jemal A and Ward E: International trends in colorectal cancer incidence rates. Cancer Epidemiol Biomarkers Prev 18: 1688-1694, 2009.

4 Ferlay J, Steliarova-Foucher E, Lortet-Tieulent J, Rosso S, Coebergh J, Comber H, Forman D and Bay F: Cancer incidence and mortality patterns in europe: Estimates for 40 countries in 2012. Eur J Cancer 49: 1374-1403, 2013.

5 Bosetti C, Levi F, Rosato V, Bertuccio P, Lucchini F, Negri E and La Vecchia C: Recent trends in colorectal cancer mortality in europe. Int J Cancer 129: 180-191, 2011.

6 Nishihara R, Wu K, Lochhead P, Morikawa T, Liao X, Qian Z, Inamura K, Kim S, Kuchiba A, Yamauchi M, Imamura Y, Willett W, Rosner B, Fuchs C, Giovannucci E, Ogino S and Chan A: Long-term colorectal-cancer incidence and mortality after lower endoscopy. N Engl J Med 369: 1095-1105, 2013.

7 Schoen RE, Pinsky PF, Weissfeld JL, Yokochi L, Church T, Laiyemo A, Bresalier R, Andriole G, Buys S, Crawford E, Fouad M, Isaacs C, Johmnson C, Reding D, O’Brien B, Carrick D, Wright P, Riley T, Purdue M, Izmirlian G, Kramer B, Miller A, Gohagan J, Prorok P, Berg C and PLCO Project Team: Colorectal cancer incidence and mortality with screening flexible sigmoidoscopy. N Engl J Med 366: 2345-2357, 2012.

8 Siegel R, Naishadham D and Jemal A: Cancer statistics, 2013. CA Cancer J Clin 63: 11-30, 2013.

9 Salas D, Vanaclocha M, Ibanez J, Molina-Barcelò A, Hernàndez V, Cubiella J, Zubizarreta R, Andreu M, Hernàndez C, Pèrez-Riquelme F, Cruzado J, Carballo F, Bujanda L, Sarasqueata C, Portillo I, de la Vega-Prieto M, Morilals J, Valentin V, Lanas A, Quintero E and Castells A: Participation and detection rates by age and sex for colonoscopy versus fecal immunochemical testing in colorectal cancer screening. Cancer Causes Control 25: 985-997, 2014.

10 Pox CP, Altenhofen L, Brenner H, Theilmeier A, Von Stillfried $\mathrm{D}$ and Schmiegel W: Efficacy of a nationwide screening colonoscopy program for colorectal cancer. Gastroenterology 142: 1460-7.e2, 2012.

11 Childs A, Mehta D and Gerner E: Polyamine-dependent gene expression. Cell Mol Life Sci 60: 1394-1406, 2003.

12 Muskiet F, Dorhout B, van der Berg G and Hessels J: Investigation of polyamine metabolism by high-performance liquid chromatographic and gas chromatographic profiling methods. J Chromatogr B Biomed Appl 667: 189-198, 1995.

13 Hiramatsu K, Takahashi K, Yamaguchi T, Matsumoto H, Miyamoto H, Tanaka S, Tanaka C, Tamamori Y, Imajo M, Kawaguchi M, Toi M, Mori T and Kawakita M: $N(1), N(12)-$ diacetylspermine as a sensitive and specific novel marker for early-and late-stage colorectal and breast cancers. Clin Cancer Res 11: 2986-2990, 2005.

14 Nakayama Y, Torigoe T, Minagawa N and Yamaguchi K: The clinical usefulness of urinary $\mathrm{N}(1), \mathrm{N}(12)$-diacetylspermine (DiAcSpm) levels as a tumor marker in patients with colorectal cancer. Oncol Lett 3: 970-974, 2012.

15 Hakkinen MR, Roine A, Auriola S, Tuokko A, Veskimäe E, Keinänen T, Lehtimäki T, Oksala N and Vepsäläinen J: Analysis of free, mono-and diacetylated polyamines from human urine by
LC-MS/MS: J Chromatogr B Analyt Technol Biomed Life Sci 941: 81-89, 2013.

16 Niemi R, Roine A, Häkkinen M, Kumpulainen P, Keinänen T, Vepsäläinen J, Lehtimäki T, Oksala N and Mäenpää J: Urinary polyamines as biomarkers for ovarian cancer. Int J Gynecol Cancer 27: 1360-1366, 2017.

17 Schroeder K, Tremaine W and Ilstrup D: Coated oral 5-aminosalicylic acid therapy for mildly to moderately active ulcerative colitis. A randomized study. N Engl J Med 317: 1625-1629, 1987.

18 Daperno M, D’Haens G, Van Assche G, Baert F, Bulois P, Maunory V, Sostegni R, Rocca R, Pera A, Gevers A, Mary J, Colombel $\mathrm{J}$ and Rutgeerts P: Development and validation of a new, simplified endoscopic activity score for Crohn's disease: The SES-CD: Gastrointest Endosc 60: 505-512, 2004.

19 Bosman F, Carneiro F, Hruban R and Theise N (ed): WHO Classification of Tumours of the Digestive system. IARC, Lyon, pp. 131-185, 2010.

20 Wang J, El-Masry N and Talbot I, Tomlinson I, Alison M and El-Bahrawy M: Expression Profiling of proliferation and apoptotic markers along the adenona-carcinoma sequence in familial adenomatous polyposis patients. Gastroenterol Res Prac 2013: 1-7, 2013.

21 Thomas $\mathrm{T}$ and Thomas TJ: Polyamines in cell growth and cell death:molecular mechanisms and therapeutic applications. Cell Mol Life Sci 58: 244-258, 2001.

22 Matsuoka A and Sakamoto T: Establishment of an ELISA system of N1, N12-diacetylspermine in human urine. Jpn J Clin Pathol 52: 328-331, 2014

23 Takahashi Y, Sakaguchi K, Horio H, Hiramatsu K, Moriya S, Takahashi K and Kawakita M: Urinary $N^{1} N^{12}$-diacetylspermine is a non-invasive marker for the diagnosis and prognosis of nonsmall-cell lung cancer. Br J Cancer 113: 1493-1501, 2015.

24 Liu L, Rao JN, Zou T, Xiao L, Wang P, Turner D, Gorospe M and Wang J: Polyamines regulate c-Myc translation through Chk2-dependent HuR phosphorylation. Mol Biol Cell 20: 48854898, 2009.

25 Snezhkina A, Krasnov G, Lipatova A, Sadritdinova A, Kardymon O, Fedorova M, Melnikova N, Stepanov O, Zaretsky A, Kaprin A, Alekseev B, Dmitriev A and Kudryavtseva A: The dysregulation of polyamine metabolism in colorectal cancer is associated with overexpression of $\mathrm{c}-\mathrm{MYC}$ and C/EBPB rather than enterotoxigenic Bacteroides fragilis infection. Oxid Med Cell Longev 2016: 2353560, 2016.

26 Nowotarski SL, Woster PM and Casero RA Jr.: Polyamines and cancer: Implications for chemotherapy and chemoprevention. Expert Rev Mol Med 15: e3, 2013.

27 Vargas A, Ashbeck E, Wertheim B, Wallace R, Neuhouser M, Thomson $\mathrm{C}$ and Thompson P: Dieatry polyamine intake and colorectal cancer risk in postmenopausal women. Am J Clin Nutr 102: 411-419, 2015.

28 Poyhonen MJ, Uusitalo UM, Kari A, Takala J, Alakuijala L and Eloranta T: Urinary excretion of polyamines: Importance of circadian rhythm, age, sex, menstrual cycle, weight, and creatinine excretion. Am J Clin Nutr 52: 746-751, 1990.

Received March 24, 2018

Revised April 19, 2018

Accepted April 23, 2018 